\title{
Theoretical Agile Process Framework for Mobile Application Development, Success Factors, and Evaluation
}

\author{
Patrick D. Cerna, Jennifer T. Carpio and Edward D. Bustillos
}

\begin{abstract}
Mobile computing has now emerged as one of the main platform for advertising, e-commerce and integration to enterprise information system. Understanding this, A comprehensive model as an established software engineering methodology was proposed for mobile application, critical success factors and evaluation through theoretical agile process framework. It consist of four major parts namely: (A) Agile Methodology appropriate for mobile application, (B) Phases of Agile Software Process, (C) Critical Success Factors for Mobile Applications Development using Agile Methodology, and (D) Evaluation Criteria for Agile Mobile Application Development. For the development of the model, a Design Science Research (DSR) was adopted which is extensively used in information systems research to solve complex problems. DSR is not only appropriate to solve organizational problems in specific domains but also adequate to produce artifacts as it is the case of our model. It can be concluded that as Agile Methodology and approach has been becoming increasingly adoption in enterprise application development, the propose model illustrate the integration of the important components, attributes and factors for a successful mobile application development and deployment.
\end{abstract}

Keywords-Agile, Mobile Application Development, CSF in Agile Methodology, SCRUM, Mobile Evaluation Criteria

\section{Introduction}

Mobile computing has now emerged as one of the main platform for advertising, e-commerce and integration to enterprise information system. Esposito [1] argues that the "Going Mobile" is a strategic plan where more conceptual that operational.

Patrick D. Cerna

Federal TVET Institute - University

Addis Ababa, Ethiopia

Jennifer T. Carpio

Adamson University / University of the East Philippines

Edward D. Bustillos

Adamson University

Philippines
The strategic plan happens because several reason such as provide a service through multiple channels, a new opportunities to provide a services, and making customer more productive. According to Wasseman [2], in many respects, developing mobile applications is similar to software engineering for other embedded applications. Common issues include integration with device hardware, as well as traditional issues of security, performance, reliability, and storage limitations. However, mobile applications present some additional requirements that are less commonly found with traditional software applications, including: (a) Potential interaction with other applications, (b) sensor handling, (c) Native and Hybrid (Mobile web) application, (d) families of hardware and software platforms, (e) security and lastly (e) user interfaces. Bearing this in mind, it can be observe that mobile devices and their applications, the software engineering process must not only be aware of the hardware device properties, but must also address project management issues and the unique aspects of mobile application development.

Agile development is used the incremental and iterative work strategy, the development life cycle is divided into smaller parts as well as revisited over and over again. It iteratively improves software based on customer feedback [2].Agile software development methodologies are based on the philosophy that emphasize the following work culture or processes: Individual and interactions over processes and tools; working software over comprehensive documentation; customer collaboration over contract negotiation and responding to change over following plan [3,4].With agile methodologies, prescribed values, principles and practices are recommended for successful software project implementation $[5,6]$. The emergence of Agile methodologies, however, can be said to have begun in the mid- 1990s, when software methodologies and techniques such as Extreme Programming (XP), Scrum, eXtreme Testing, Crystal Family of Methodologies, Dynamic Systems Development Method (DSDM), Adaptive Software Development (ASD), and Feature-Driven Development (FDD) began to emerge. Since then, Agile software development methods have gained popularity and have become increasingly important to a significant number of software development organizations $[7,8]$. Agile software development solutions can be seen to provide a good fit for the development of mobile applications [9]. Thus, agile is a fit model for the development of mobile applications [10].

As mobile applications become more complex, moving beyond inexpensive recreational applications to more business critical uses, it will be essential to apply software engineering 
processes to assure the development of secure, high-quality mobile applications. Understanding this, there is a need to create a appropriate model as an established software engineering methodology for construction mobile application through theoretical agile process framework. It is evident that there has been no study and there is a need to develop a theoretical agile process model for mobile application development and evaluation

\section{RELATED WORKS}

Altarawneh and El Shiekh [11] proposed theoretical agile process framework for web applications development in small software firms. Their proposition is to modify the XP life cycle and to add a lightweight project management activity at the beginning of a project. The proposed framework consists of the following steps: (a) Start with small web projects, (b) adopt the modified XP process model, (c) Apply XPMM and (d) Education and training.

Ferdiana [12] introduce an agile software engineering framework for evaluation mobile application development called MASEF which will guide novice developers to develop and evaluate a mobile application development in agile way. MASEF is a composition between mobile application developments with agile XP approach. MASEF has the architecture layer, execution phase, and also requirement adoption [11] .

Similary, Wasserman [2], conducted a study on software engineering issues for mobile application development which explains an overview of important software engineering research issues related to the development of applications that run on mobile devices. Among the topics are development processes, tools, user interface design, application portability, quality, and security. He reiterated that while the large number of mobile applications makes it appear that software development processes for them are well understood, there remain a large number of complex issues where further work is needed [2].

Vithani [13] develop a model for mobile application development lifecycle (MADLC), which includes the following phases: Identification, Design, Development, Prototyping, Testing and Maintenance. The model lifecycle has been used for over a year in developing Android mobile applications. It addresses some of the distinguishing characteristics of mobile applications like lifespan, complex functionalities, fewer physical interfaces, more number of screens for interaction, battery and memory usage, cross platform development and maintenance.

Rahimian and Ramsin [14] propose an appropriate framework for the development of mobile systems based on of Agile and risk-based methodologies which called Hybrid Method Engineering (HME). It is based on a combination of agile methodologies, ASD and New Product Development
(NPD). The outcome of this research paper is the Hybrid Methodology Design Process. Similarly, Almasri [15]develop suitable process model that conforms to the requirement of mobile application, we are going to investigate agile development methods to find a way, making the development of mobile application easy and compatible with mobile device features.

On the other hand, Valdya [16], discusses an agile framework that offers a repeatable process for building cloudbased applications. The proposed framework can expect to gain tremendously by investing into an Agile framework that supports Cloud development. It will help the organization to be ready and prepared as our customers look for guidance and help in developing these new generations of application [16].

\section{METHODOLOGY}

Relevant literature on Agile Methodology and its application to mobile application development, success factors, and evaluation was critically reviewed using literature survey as primary data. For the development of the model, a Design Science Research (DSR) was adopted which is extensively used in information systems research to solve complex problems. DSR is not only appropriate to solve organizational problems in specific domains but also adequate to produce artifacts as it is the case of our model. The designscience paradigm has its roots in engineering and the sciences of the artificial [17]. Design science knowledge is manifested in the form of artifacts - constructs, models, frameworks, architectures, design principles, methods, and/or instantiations - and design theories [18].Using the six steps of DSR (Figure 1) as proposed by Peffers et al. [18], the proposed model of Theoretical Agile Process Model for Mobile Application Development and Evaluation has been designed. 


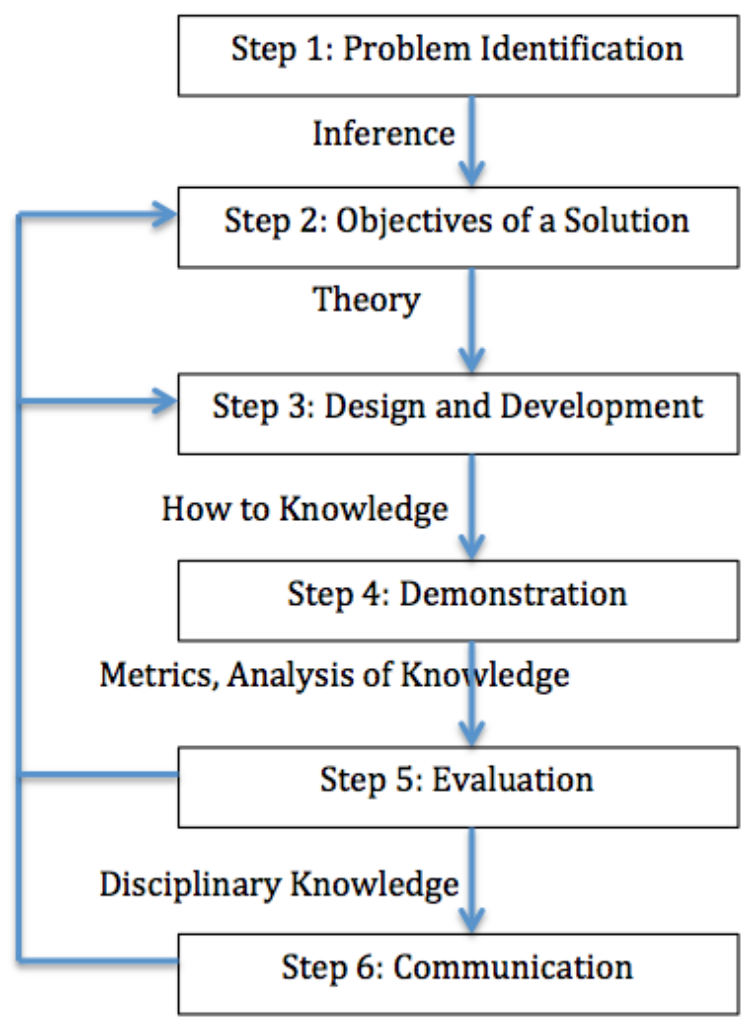

Figure 1. Steps of Design Science Research [18]

Table 1 presents that details description of each of the step in DSR in the formulation of Agile Process Model of Mobile Application Development and Evaluation. It starts by identifying the problem through critical review of literature on Agile Methods in Mobile application development and setting up the objective of the formulating a model that can guide both academic researchers and software practitioners. Next is to introduce the model to the receiving community of researchers and practitioners, evaluating the model through surveys, workshop and adopt the critical success factors of Agile Methodology in Mobile Application Development.

TABLE 1: DSR-BASED STEPS IN DEVELOPING IT GOVERNANCE FRAMEWORK

\begin{tabular}{|c|l|}
\hline Steps & \multicolumn{1}{c|}{ Description } \\
\hline $\begin{array}{c}\text { Step 1: Problem } \\
\text { Identification }\end{array}$ & $\begin{array}{l}\text { Upon a critical review of literature, it has been found out } \\
\text { that there has been no Theoretical Agile Process Model for } \\
\text { Mobile Application Development and Evaluation }\end{array}$ \\
\hline $\begin{array}{c}\text { Step 2: Objectives of the } \\
\text { Solution }\end{array}$ & $\begin{array}{l}\text { Propose an appropriate model of Theoretical Agile Process } \\
\text { Model appropriate for Mobile Application Development } \\
\text { and Evaluation that can be adopted by academic research } \\
\text { and software practitioners }\end{array}$ \\
\hline $\begin{array}{c}\text { Step 3: Design and } \\
\text { Development }\end{array}$ & $\begin{array}{l}\text { Develop a model through critical review of literature on } \\
\text { Agile Process Model applied in web-based application, } \\
\text { cloud-based and enterprise systems. Identify the gaps of } \\
\text { previous research on Agile Model in Mobile Application } \\
\text { both in academic and practitioner setting }\end{array}$ \\
\hline Step 4: Demonstration & $\begin{array}{l}\text { Introduce the develop model with the software development } \\
\text { practitioner involved in mobile application development } \\
\text { and academic research involve in Agile Software } \\
\text { Methodology }\end{array}$ \\
\hline Step 5: Evaluation & $\begin{array}{c}\text { Evaluating the model by observing its success through } \\
\text { surveys, workshops and interviews with researchers and } \\
\text { practitioners }\end{array}$ \\
\hline
\end{tabular}

\section{PROPOSED FRAMEWORK AND DISCUSSION}

The propose model as presented in Figure 2 illustrates components and integration of Agile Process Framework for Mobile Application Development and Evaluation. It consist of four major parts namely: (A) Agile Methodology appropriate for mobile application, (B) Phases of Agile Software Process, (C) Critical Success Factors for Mobile Applications Development using Agile Methodology, and (D) Evaluation Criteria for Agile Mobile Application Development. In the top, the suitable and appropriate agile methodology approach can be selected among SCRUM, Extreme Programming (XP) and Feature Driven Development. SCRUM is an iterative and incremental method whose purpose is to help development teams to concentrate on established goals and minimize the work done on less important tasks, which is best suited for mobile application development [19].

$\mathrm{XP}$ is one of a lightweight and iterative informal mobile software development methodology [20]. This method also turns out to be quite useful for mobile app development as it helps you to launch the project and then incorporate the required changes as per the requirement. Feature driven development on the other hand is yet another agile methodology for mobile app development processes that is model driven [20].

In the middle represent the eight (8) phases of agile software process with most of these elements are well-known agile practices [21] which specialized for mobile software development. According to Ambrahamsson [21]this agile architecture line of the projects integrates the systematic piecemeal growth of software architecture. The Mobile TestDriven Development (MTTD)practice involves writing tests before actual implementation, automating unit testing procedures, and acceptance testing all features with the customer [21].The bottom represents the critical success factors in mobile application development using Agile Methodology using the model proposed by Chow and Cao [].This key factors which may affect the success or failure of an Agile software project includes: (a) organizational factors representing the management commitment and organizational environment, (b)people factors represented by team capability and customer involvement, (c) process factors such as the project management process and project definition process, technical factors that corresponding to Agile software development techniques and the delivery strategy and (e) project factors such as project nature and project type. 
Proc. of The Seventh International Conference on Advances in Computing, Electronics and Communication - ACEC 2018 Copyright $\odot$ Institute of Research Engineers and Doctors, USA. All rights reserved.

ISBN: 978-1-63248-157-3 doi: 10.15224/978-1-63248-157-3-09

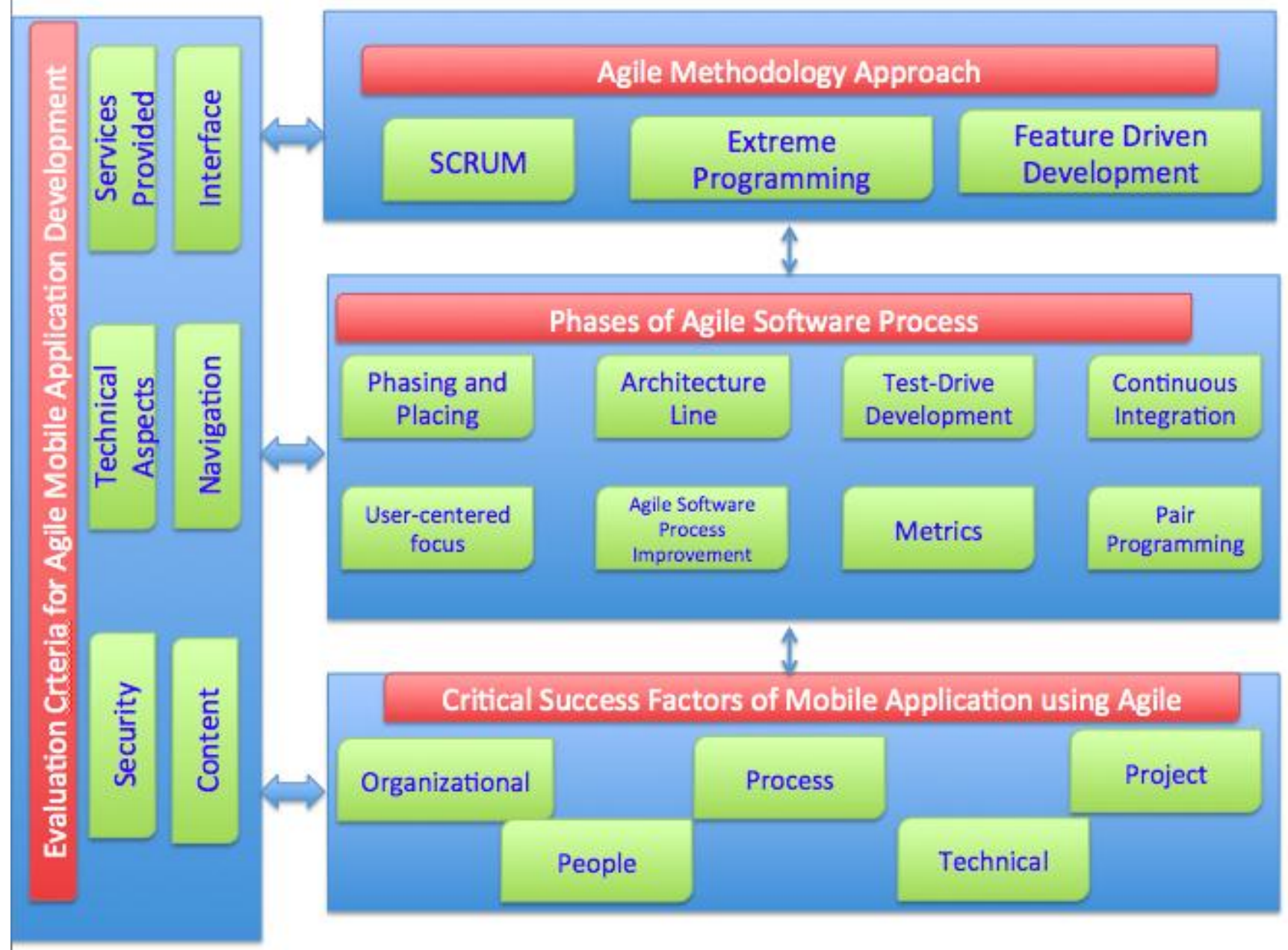

Figure 2. Theoretical Agile Process Framework for Mobile Application, Success Factors and Evaluation

Within these proposed framework a general and prescribed evaluation criteria for Mobile Application Development. According to Zarifopoulos and Economides [23], in evaluating a mobile website there are factors that need to be consider which includes Interface, navigation, offered services, content, reliability, and technical aspects. Zarifopoulos and Economides [23] utilize these evaluation criteria in proposing a Mobile Banking Evaluation Framework (MoBEF) to evaluate the mobile banking services of candidate banks, and for bank managers to improve their mobile banking services. Furthermore, Al-Khalifa [24], also utilized this evaluation criteria in providing an evaluation framework dedicated to the assessment of universities' mobile websites and also to identify trends and gaps in current services provided in universities' mobile websites.

\section{v. PROPOSED FRAMEWORK AND DISCUSSION}

This research is deeply rooted with the main gaps that there has been no establish Agile Process Model for Mobile Application Development, Critical Success Factors and Evaluation. Bearing this in mind, it is timely that prior to its implementation a guided framework for mobile application developers and academic researchers. As Agile Methodology and approach has been becoming increasingly adopted in enterprise application development, the propose model illustrate the integration of the important components, attributes and factors for a successful mobile application development and deployment. 


\section{References}

[1] D. Esposito, Architecting Mobile Solutions for the Enterprise. Microsoft Press. 2012

[2] A. I. Wasserman. Software engineering issues for mobile application development. ACM Transactions on Information Systems, 2010. Pp 1-4. https://doi.org/10.1145/1882362.1882443

[3] Beck, K. Beedle, M. van Bennekum, A. Cockburn, A. Cunningham, W. Fowler, M. Grenning, J. Highsmith, J. Hunt, A. Jeffries, R. Kern, J. Marick, B. Martin, R. Mellor, S. Schwaber, K. Sutherland, J \& Thomas, D. 2001. Manifesto for Agile Software Development. (30.5.2013) http://agilemanifesto.org/iso/en/manifesto.html

[4] R. Pressman. Software Engineering: A Practitioner's Approach. McGraw Hill, 7th Edition.2010. pp 66

[5] E. R. Keith. Agile Software Development Processes A Different Approach to Software Design. 2002. Available on http://www.cs.nyu.edu/courses/spring03/V22.0474-

001/lectures/agile/AgileDevelopmentDifferentApproach.pdf

[6] E/ Mnkandla and B. Dwolatzky. Agile Software Methods. Idea Group Inc. 2007

[7] A. Marchenko and P. Abrahamsson, "Scrum in a multi project environment: An ethnographically-inspired case study on the adoption challenges," in Agile, 2008. AGILE '08. Conference, August 2008, pp. 15-26. [Online]. Available: http://dx.doi.org/10.1109/Agile.2008.77

[8] B. Boehm, "Get Ready for Agile Methods, with Care," IEEE Computer, pp. 64- 69, January, 2002

[9] R. Holler, "Mobile application development: a natural fit with agile methodologies," VerisonOne, LLC, Alpharetta, 2006.

[10] Abrahamsson, P., Warsta J. New Directions on Agile Methods: A Comparative Analysis. In Proceedings of International Conference on Software Engineering (ICSE25), 2003.

[11] Altarawneh, H., \& Shiekh, A. El.A Theoretical Agile Process Framework for Web Applications Development in Small Software Firms. 2008 Sixth International Conference on Software Engineering Research, Management and Applications, 2008. pp. 125-132. http://doi.org/10.1109/SERA.2008.14

[12] R. Ferdiana. Agile Software Engineering Framework for Evaluating Mobile Application Development. International Journal of Scientific \& Engineering Research Volume 3, Issue 12, 2008.

[13] Kumar, A., \& Vithani, T. A comprehensive mobile application development and testing lifecycle. 2014 IT Professional Conference, I, 1-27. http://doi.org/10.1109/ITPRO.2014.7029289

[14] V. Rahimian and R. Ramsin. Designing an Agile Methodology for Mobile Software Development: A Hybrid Methodology approach. Second International Conference on Research Challenges in Information Science. 2008. Pp. 337-342.

[15] Almasri, A. K. A Proposed Hybrid Agile Framework Model For Mobile Applications. International Journal of Software Engineering \& $\begin{array}{llll}\text { Applications } & \text { (IJSEA), } & 7(2), & 2006 .\end{array}$ http://doi.org/10.5121/ijsea.2016.7201

[16] Vaidya, K. (2011). An Agile Process Framework for Cloud Application Development. Computer Sciences Corporation

[17] H. Simon, The Sciences of Artificial, 3rd edn., MIT Press, Cambridge, MA, 1996

[18] K. Peffers, T. Tuunanen, C. E. Gengler, M. Rossi, W. Hui, V. Virtanen, and J. Bragge, Thedesign science research process: a model for producing and presenting information systems research, 2006.

[19] K. Schwaber and M. Beedle, "Agilè Software Development with Scrum," 2002.

[20] M. Abouelela and L. Benedicenti, "Bayesian Network Based XP Process Modelling," arXiv preprint arXiv:1007.5115, 2010

[21] Abrahamsson, P., Salo, O., Ronkainen, J. \& Warsta, J. (2002) Agile software development methods: Review and analysis, VTT publication 478, Espoo, Finland, 107p.
[22] T. Chow and D.-B. Cao, "A survey study of critical success factors in agile software projects," J. Syst. Softw., vol. 81, no. 6, pp. 961-971, 2008

[23] Zarifopoulos, M. and Economides, A.A "Evaluating mobile banking portals",International Journal of Mobile Communications, Vol. 7 No. 1, 2009. pp. 66-90.

[24] Al-Khalifa, H. S. A framework for evaluating university mobile websites. Online Information Review, 38(2), 2014. 166-185. http://doi.org/10.1108/OIR-12-2012-0231 